\title{
PASSAGEM DA COMPREENSÃO Ȧ VERDADE: CONTRIBUIÇÃO DO ESTRUTURALISMO À TEORIA LACANIANA DA PSICOSE
}

Léa Silveira Sales

Aluna do doutorado em Filosofia da UFSCar (Linha de pesquisa: Filosofia da Psicanálise); bolsista da Capes.
RESUMO: A argumentação procura mostrar que é a inserção na racionalidade estruturalista que finalmente conduz Lacan a providenciar a descrição de um dispositivo específico na causação da psicose, permitindo, através da distinção entre conhecimento e verdade, a superação dos impasses de sua tese de doutorado, então baseada em critérios de assentimento social e na tentativa de sobrepor explicação e compreensão.

Palavras-chave: Estruturalismo, psicanálise lacaniana, teoria da psicose.

ABSTRACT: Passage from comprehension to truth: structuralism's contribution to the Lacanian psychosis theory. From comprehension to truth: structuralism's contribution Lacanian theory of psychosis. The argument tries to show that it is the insertion into the structuralist rationality that finally leads Lacan to provide the description of a specific device in the causation of psychosis, allowing, through the distinction between knowledge and truth, the overcoming of the impasses of his doctoral thesis, then based on criteria of social consent and on the attempt to overlap explanation and comprehension.

Keywords: Structuralism, Lacanian psychoanalysis, psychosis theory.

A partir dos anos 1950, Lacan passa a desenvolver - e a aplicar a toda a teoria psicanalítica — uma concepção de linguagem segundo a qual ela cria "uma ordem de ser nova" (LACAN, 1953-1954/1975, p.263), restringindo sua única forma de relação com a realidade ao modo da negação. Apoiandose em Santo Agostinho, abraça a idéia de que uma significação não remete a uma coisa tangível, mas tão-somente a outra significação. De acordo com essa abordagem, não existem definições ostensivas porque ensaiar ingenuamente indigitar 
a realidade é um ato incapaz, por si mesmo, de garantir com exatidão o que está sendo apontado. Mesmo quando nos esforçamos para ligar, com o gesto indicador, um nome a um espaço discreto do real, não escapamos da ambigüidade própria tanto ao nome quanto ao ato da indicação, que exigem, ambos, a referência à totalidade da linguagem, pois a ela compete a discriminação de seus respectivos lugares estruturais. Não há indicação em estado bruto: ela já surge de um mapeamento lingüístico que abre o contexto do espaço do objeto como objeto a ser re-conhecido (no caso da psicanálise, conforme o desejo inconsciente). Não há objeto em estado bruto: a linguagem, quando "atinge a realidade”, já encontra nela algo de sua própria natureza (LACAN, 1957-1958/1998, p.50)

Jamais designando diretamente um referente na realidade, a existência da linguagem possui, assim, um teor de fatalidade porque cava um fosso entre o homem e as coisas sensíveis, abolindo estruturalmente qualquer possibilidade de imanência no sentido de um contato pré-reflexivo com o mundo: “[...] os significantes só manifestam a presença da diferença como tal e nada além disso. Logo, a primeira coisa que ele implica é que a relação do signo à coisa seja apagada" (LACAN, 1961-1962, p.58). Assim, o isolamento do significante com relação ao significado — operação pela qual o primeiro é visto como algo que só manifesta a diferença — garante a permanência de uma ordem explicativa do desejo radicalmente divorciada de um trato realista.

Essa distância entre realidade e discurso é forte ponto de conjunção com o pensamento de Kojève, com o momento em que ele procede a uma identificação entre erro e verdade:

“A verdade é mais do que uma realidade: é uma realidade revelada; é a realidade mais a revelação da realidade pelo discurso. Há, portanto, no seio da verdade, uma diferença entre o real e o discurso que revela. Mas uma diferença se atualiza sob a forma de uma oposição, e um discurso oposto ao real é, precisamente, um erro. Só há, portanto, realmente uma verdade lá onde tenha havido um erro." (KOJÈVE, 1947, p.463)

A verdade é o próprio descompasso entre realidade e discurso. É, portanto, de outro ângulo, a verdade da impossibilidade da verdade porque nada da "realidade" terá lugar na linguagem. Dessa forma, a verdade, cuja forma é necessariamente discursiva - como tal, recoberta pela inépcia própria a qualquer discurso —- é aquilo que erra quanto à apreensão das coisas. O discurso não possui meios de sair de si mesmo; não podemos dar as costas à linguagem para "vermos" o que há por detrás porque toda visão encontra-se estruturalmente condicionada pela própria linguagem. A noção de mundo se reduz, assim, à reiteração, na estrutura, de uma potência para ser dito, fazendo parte da própria condição da linguagem 
a condução do sujeito à crença no objeto como imagem de um mundo real e acessível, o que é apenas outra forma de dizer que o significante determina o significado, que o simbólico determina o imaginário.

A conseqüência epistemológica da aplicação dessa concepção de linguagem é evidente e vem de par com uma insistente crítica da atitude de compreensão, inaugurando, quanto a este ponto, um caminho exatamente oposto ao percorrido em sua tese de doutorado (1932/1987), quando Lacan se esforçava para afastá-la do espiritualismo de Jaspers e para incluí-la num quadro de abordagem objetiva da personalidade. Contra Dilthey, providenciar-se-ia sua explicação mediante a discriminação das relações de compreensão. Sabemos que nenhum passo da teoria lacaniana é indiferente a uma reflexão epistemológica. Aqui, a noção de linguagem abraçada denuncia a compreensão como equívoco do apego à segurança imaginária e a uma precipitação intelectual distanciadora da verdade; por isso “[...] cada vez que vocês compreendem, é aí que começa o perigo” (LACAN, 1958-1959, p.6).]

É preciso sublinhar a importância de tal modificação no pensamento lacaniano: antes havia um total recobrimento entre paranóia e verdade/conhecimento, toda abordagem de objeto tendo origem na rivalidade narcísica; já o ponto de vista do simbólico anuncia uma dimensão discursiva não delirante, desde que ceifada a vontade de compreender: “[...] o importante não é compreender, é atingir o verdadeiro. [...] [compreender] prova que temos todos alguma coisinha de comum com os delirantes" (LACAN, 1955-1956/1981, p.59). Uma coisa merece ser destacada nessa passagem: doravante, é possível vislumbrar um espaço para a verdade que não está contaminado pelo delírio, o resultado sendo sua imediata dissociação do conhecimento. A origem do objeto como produção imaginária continua a mesma, mas a psicanálise, com a sustentação do inconsciente reformulado em termos de estrutura simbólica, abre um novo espaço para a verdade que, enquanto verdade acessível, está além do espaço do objeto e do fenômeno. Tal estratégia precisa, então, ressituar a descoberta freudiana não mais como objeto de um conhecimento, mas como alvo de um testemunho: verdade sujeita a uma constatação em que o agente se encontra implicado, tanto como quem empreende a ação de constatar, quanto como quem reconhece tratar-se ali de uma verdade que lhe diz respeito.

Esse movimento é intensamente reiterado durante toda a década de 1950. Nele, a dissociação entre conhecimento e verdade parece indicar uma dissociação entre conhecimento e ciência. O ideal de ciência permanece presente de maneira muito forte - investido nas leis do significante - , mas o conhecimento é rechaçado como fenômeno ilusório e desencaminhador, de forma que unir aquela verdade testemunhada à qualificação de ciência é resultado inevitável da abordagem estruturalista do inconsciente. Lacan insiste, a partir daí, na distinção 
entre sujeito da fala e sujeito do conhecimento, demonstrando, em fidelidade à perspectiva do concreto, que seu repúdio ao realismo ingênuo não lhe conduz a um apego ao idealismo, pelo contrário. Pois um dos motivos para nos atermos ao sujeito que fala em detrimento do que conhece é que este é ideal e problemático na medida que apenas suposto como sombra e duplo dos objetos, enquanto o primeiro impõe-se necessariamente a partir da constatação direta do discurso, sem intermediações metafísicas. O objeto, se tomado como existente por-si, como embuste; o conhecer posto em xeque pela revelação da posição secundária da realidade diante do desejo: “[...] Freud fez apagar-se para sempre o bom sujeito do conhecimento filosófico, aquele que encontrava no objeto um status de todo descanso, diante do mau sujeito do desejo e de suas imposturas" (LACAN, 1959a/1966, p.716).

Assim, a introdução do simbólico permite o estabelecimento de um ponto de vista diferenciado quanto à constituição concomitante do grupo sujeito-objetooutro-realidade. Tal como no artigo sobre a família (LACAN, 1938), ela segue sendo defendida, mas a colocação em segundo plano do crivo dualista em favor da efetividade da estrutura garante agora uma saída epistemológica mais interessante. Lacan comenta, no Seminário 5, uma distância com relação a Melanie Klein por trás da qual é evidente a expressão de uma revisão de sua antiga tese de equivalência entre fenômeno de conhecimento e fenômeno paranóico (LACAN, 1932/1987). Klein, ao perceber, ainda que de modo exemplar, a complexidade da relação da criança com o desejo do outro, teria permanecido alheia à imposição do desejo do Outro. Ao formular o movimento de constituição do desejo “ [...] simplesmente no confronto da criança com o personagem materno, ela atingiu uma relação especular [...]” (LACAN, 1957-1958/1998, p.271-2), sem meios de sair do nível superficial e perigosamente psicológico da projeção que situaria a realidade como delírio subjetivo:

"No fim das contas, nada nessa dialética pode nos fazer sair de um mecanismo de projeção ilusória, de uma construção do mundo a partir de uma espécie de autogênese de fantasias primordiais. A gênese do exterior como lugar do ruim permanece puramente artificial, e submete todo o acesso ulterior à realidade a uma pura dialética de fantasia." (LACAN, 1957-1958/1998, p.272)

Chamar a atenção nesse momento para a presença primordial do pai, figura do terceiro e da lei, traduz, nesse sentido, a necessidade de um campo transcendental para que seja possível pensar a formação da realidade sem resvalar nos pólos opostos do realismo e do idealismo; sem a verificação de objetividades ingênuas, sem a atribuição de caráter psicológico à realidade. Esta, perspectivada em função da linguagem, não deixa de ser o resultado de um processo racional 
extra-psicológico. Da mesma forma, de outro ângulo, embora a verdade habite o erro, retirando daí seu caráter negativo, esse erro é produto de um processo cuja estrutura pode ser definida. Trata-se do valor transcendental ${ }^{1}$ da saída encontrada por Lacan a partir do estruturalismo: pensar o esquema, tido por racionalidade do significante, sem, no entanto, desprezar os dados empíricos que, no caso, vêm da clínica.

Na verdade, a experiência possui, na psicanálise lacaniana, relações muito singulares com a teoria, relações que, em diversos pontos, as tornam indiscerníveis, pois aquilo que nela se oferece não é objeto externo à teoria, senão a própria fala que a constitui em discurso revelador da estrutura da fala. A fala, atualização da estrutura, não é exterior à estrutura. Dessa forma, a epistemologia lacaniana, paradoxalmente baseada no transcendental da estrutura concreta, decerto não é empirismo, mas também não é racionalismo, pois que encontra seu esquema racional no próprio "dado” (da fala). Observe-se, aí, o quanto a disposição dos elementos “dado”, “empírico”, “teoria”, “razão” se interpenetram, afastando o lacanismo das referências filosoficamente clássicas. Apesar disso, a inspiração kantiana, nesse momento, é clara e explicitamente sustentada por Lacan (19571958/1998, p.50).

Haveria, portanto, um nível anterior ao trabalhado por Klein e que o justificaria em última instância. Um nível racional explicativo do desejo por trás da compreensão como resposta a uma demanda, demanda esta cujo nível é o mesmo da projeção imaginária que fixa os objetos em objetos conhecidos. Sua verdade, inaparente, deve ser buscada na estrutura simbólica do desejo como estrutura da fala.

Notemos aqui que, na medida que o simbólico é pensado como estrutura, sob certo ângulo, exterior ao homem e maior do que ele, essa perspectiva é oposta à idéia de uma realidade subjetivamente conformada. Interpretar Lacan dessa forma não seria fazê-lo retornar ao psicologismo rejeitado — visto que esse sujeito é completamente repensado fora dos padrões psicológicos —-, mas arriscaria comprometê-lo com elementos de um idealismo que ele repudia. Sim, a realidade é uma rede discursiva e o objeto sempre implica a estrutura do sujeito. Porém não porque esta seja o ponto de determinação, mas porque ambos são efeitos, inalienáveis, de uma outra estrutura. A estrutura que enforma a realidade como ficção não é a do sujeito, mas a do inconsciente (como linguagem), à qual ele também se encontra submetido, tratando-se, antes, de uma ficção transcendentalmente formatada.

\footnotetext{
${ }^{1}$ Ou seja, o valor de um campo que dispõe as condições lógicas da possibilidade (a priori) da apreensão do sensível (da experiência, portanto). Lembremos aqui de Ricoeur (1970) comentando que o inconsciente estruturalista é como um inconsciente kantiano que, no entanto, não faz referência a um sujeito transcendental.
} 
Uma das questões que correm em paralelo a esse deslocamento do conhecimento em sua relação com a verdade é, evidentemente, a definição em moldes estruturalistas da especificidade do mecanismo da psicose, até então atrelado a uma valoração positiva da compreensão. Sabemos não ser um problema de menos peso, uma vez que tal afecção ocupa no pensamento de Lacan o lugar de prevalência que Freud destinava à neurose, devendo-se a ela a conformação da estrutura da personalidade na fase psiquiátrica inicial e a justificação última para a teorização de uma nova clínica. Aliás, seu interesse pela psicose é mesmo anterior a seu interesse pela psicanálise. Não é difícil perceber, nesse momento, a contribuição que o estruturalismo oferece à questão: sobre o fundo de uma teoria homogênea - a do simbólico como estruturante do sujeito — torna-se por fim possível teorizar o mecanismo específico da psicose. Ou seja, o que o estruturalismo fornece a Lacan, em especial no desenvolvimento de seu terceiro seminário, é uma teoria formalizada da determinação diferencial da psicose encaixada numa teoria mais geral da constituição do sujeito. A colocação da psicose sob a dependência do modo de operação de um dos elementos do Édipo — o Nome-do-Pai — faz com que sua diferença frente à neurose seja de ordem estrutural, saída do círculo explicativo de sua tese de doutorado, o qual se achava baseado, no final das contas, em critérios de assentimento social.

Cabe perguntar agora se isso significa que a constituição da psicose ter-seia tornado fato contingente, não apresentando mais nada de essencial a dizer acerca da verdade última da subjetividade em geral. É o próprio Lacan quem nos dissuade dessa interpretação:

"Se não somos capazes de perceber que há um certo grau, não arcaico, a situar em algum lugar do lado do nascimento, mas estrutural, no nível do qual os desejos são, propriamente falando, enlouquecidos; se para nós o sujeito não inclui na sua definição, na sua articulação primeira, a possibilidade da estrutura psicótica, jamais seríamos mais do que alienistas." (1961-1962, p.273)

Mas, nesse caso, é preciso descobrir o caminho que permite a compatibilidade entre alguma proximidade na origem e o distanciamento necessário para o fornecimento de mecanismos estruturalmente diferentes.

Esse caminho se explica pela análise das relações entre Verwerfung (forclusão/ preclusão), Bejahung (afirmação) e Aut $\beta$ ossung (expulsão). Pois a teoria lacaniana da psicose nasce de um comentário do texto A negação no qual Freud pensa a delimitação originária de um espaço psíquico através da operação intelectual do juízo como operação de desejo frente ao objeto da experiência de satisfação. Ele distingue aí duas espécies de juízo: 1. o juízo de atribuição, ligado ao euprazer inicial, pelo qual negar uma qualidade a uma coisa corresponde a situá-la 
em espaço externo ao eu. Primitivamente, ele liga o que é ruim (do ponto de vista da satisfação da pulsão) ao exterior e, o que é bom, ao que pertence a si mesmo no próprio momento de delimitação inicial desse "si mesmo”. 2. o juízo de existência, ligado ao eu-realidade, derivado, relacionado com a necessidade de averiguar a validade de uma representação (interna, outrora originada na percepção) como percepção renovada (externa), ou seja, como a tentativa de reencontrar o objeto. Encontrar-se-ia igualmente implicado, em passo posterior, na questão da diferenciação interior/exterior. Assim, mesmo nas etapas mais sofisticadas de um raciocínio qualquer, o juízo reitera a seleção regulada pelo movimento pulsional. Em seguida, Freud estabelece uma correspondência entre o ato de afirmar e pulsões de vida e, por outro lado, entre o ato de negar e pulsões de morte:

"Sua polaridade [do julgar] parece corresponder à oposição dos grupos pulsionais que supusemos existirem. A afirmação - como substituto da união - pertence a Eros; e a negação — sucessora da expulsão — à pulsão de destruição.” (FREUD, 1925/1989, p.256)

Lacan, então, toma o termo em alemão Bejahung para se referir ao momento mítico de uma afirmação originária relacionada a um primeiro juízo de atribuição que separou o real, como o fora, de tudo aquilo que pode vir a fazer parte de cadeias significantes inconscientes.

É comum esse passo ser interpretado como o estabelecimento de uma anterioridade da afirmação com relação à negação. Isso porque, no texto de Freud, a Verneinung, negação utilizada no discurso pela via do uso da palavra "não", tem essa afirmação originária do juízo de atribuição como sua condição lógica. Mas se levarmos em conta que a contrapartida concomitante da afirmação é a expulsão e ainda que, para Lacan, a inscrição - afirmativa — de um significante não pode deixar de ser, por si mesma, uma espécie de negação, tal anterioridade encontra-se sem fundamento. Afirmar um significante primordial, quando se tem em vista a forma com que é definido, ou seja, sua pertinência de essência a uma estrutura, é, ao mesmo tempo, negar todos os demais, além de negar a possibilidade da imanência discutida no início desse artigo. É, aliás, exatamente essa simultaneidade entre afirmação e negação que descreve o momento de criação do real como o fora da simbolização para o sujeito.

O que desponta nesse raciocínio é a necessidade de se distinguir três tipos de negação: Aut $\beta$ ossung — negação que corresponde à expulsão no momento da Bejahung; Verneinung — a negação intelectual em que alguém rejeita um conteúdo recalcado pelo uso verbal do "não”; Verwerfung - a negação específica do mecanismo implicado na psicose. 
O problema é que o negado pela Verwerfung é a Bejahung e isso dá margem a confundi-la com a Aut $\beta$ ossung, apesar de se tratar de operações diferentes e precisamente definidas em seus valores. Balmès (1999), por exemplo, defende a existência dessa ambigüidade, argumentando ser necessário diferenciar, nos textos de Lacan, os elementos que contribuiriam para uma identificação entre Aut $\beta$ ossung e Verwerfung de outros que permitiriam sua distinção. Entende que o caminho da identificação deve ser descartado, uma vez que expulsão diz respeito a qualquer constituição de sujeito enquanto forclusão concerne apenas ao psicótico. No entanto, talvez tal caminho não exista no texto lacaniano. Vejamos qual a sentença, considerada indutora da leitura rejeitada: "O processo de que se trata sob o nome de Verwerfung [...] é exatamente o que se opõe à Bejahung primária e constitui como tal aquilo que é expulso" (LACAN, 1956/1966, p.387). Ela pode, sem nenhum problema exegético mais complicado, ser entendida da seguinte forma: quando a Verwerfung se opõe à Bejahung ela instaura um outro tipo de expulsão, constitutiva do real na psicose e diferente da Aut $\beta$ ossung. O trecho “constitui como tal o que é expulso", refere-se àquilo que é expulso no desfecho psicótico, pois se trata justamente de administrar o caráter específico dessa expulsão, na sua diferença para com a outra expulsão que tem lugar quando do surgimento do real para o neurótico.

A indicação prematura do tipo de circunscrição implicada no real, dentro de uma teoria que estabelece a estrutura simbólica como fato de partida, permite perceber que a alternativa entre assunção de um simbólico déjà-là ou criação estrito senso do simbólico, ao contrário do que defende Balmès, é uma falsa questão. "Simbolização primordial" só pode ser pensada como criação do ponto de vista do sujeito que então se constitui. Trata-se de uma questão de perspectiva e não de diferença de natureza. Ascender à linguagem, utilizando-a em registro ressonante ao Outro, é ter o simbólico "como que" criado por uma primeira afirmação mítica que inaugura o sistema das Vorstellungen. Mas ele não é, nesse sentido, criado em si, nem surge ex nihilo: o sujeito já nasceu banhado de linguagem. A questão é saber como isso vai atingi-lo, conformando o modo de sua relação estrutural com a totalidade da linguagem, a forma pela qual ela vai se tornar uma linguagem subjetivada.

A afirmação de que a Aut $\beta$ ossung " [...] é tão-somente o reverso negativo de uma só e mesma operação, cujo lado positivo é Bejahung” (BALMÈS, 1999, p.73) pode ser encontrada de saída no texto lacaniano. Não se trata de uma hipótese de leitura cujo valor seria equivalente ao de outra hipótese, a da tendência, em alguns pontos, à indistinção entre Aut $\beta$ ossung e Verwerfung, porque esta pode ser descartada sem prejuízo ao rigor da pesquisa. Pelo contrário, tudo indica que apostar, desde o início, na distinção clara entre as duas operações é a forma mais coerente e plausível de lidar com o assunto. 
Da mesma forma, toda a discussão que se segue no texto de Balmès, sobre a qual operação — afirmação ou negação — atribuir anterioridade lógica, se baseia no esquecimento de que ambas, no nível do par Bejahung/Aut $\beta$ ossung, são a mesma operação, não havendo contradição entre o texto da discussão com Hyppolite tal como publicado nos Escritos e tal como aparece no Seminário 1. Ambas, não podendo ser separadas devido à lógica de seu funcionamento, se situam no mesmo nível originário.

Assim, se não entendermos essa discussão como algo isolado, mas respondendo a questões principais da obra, é preciso lembrar a insistência de Lacan na função originariamente negativa da linguagem: a Aut $\beta$ ossung não pode ser algo posterior à Bejahung. A melhor forma de descrever a relação entre ambas é: Bejahung é Aut $\beta$ ossung e vice-versa — no sentido de que o mito do fora é o mesmo mito do dentro, de que "[...] nada existe senão sobre um suposto fundo de ausência" (LACAN, 1956/1966, p.392) — cada termo designando apenas um aspecto diferente da mesma operação que inscreve um significante para um sujeito na mesma medida que, para fazê-lo, o destaca do restante da cadeia. Operação que, por sua vez, pode vir a ser rejeitada por uma outra, chamada Verwerfung de forma que, se nesta não há Bejahung, também não há Aut $\beta$ ossung.

A Verwerfung é uma expulsão da Bejahung e, se assim o é, está fora de questão a existência, na psicose, dessa Aut $\beta$ ossung discutida acima. Todo sujeito, mesmo o psicótico, já nasce imerso no Outro, submetido à presença espalhada do simbólico. Mas a aceitação do significante que representa a presença desse Outro como destino da fala pode não ocorrer.

Freud não chegou a relacionar uma teoria da psicose com esse termo, mas, ao discutir o fenômeno alucinatório do Homem dos Lobos (1918/1989), afirma que ele "suprimiu” [verwarf] a castração sem construir nenhum juízo sobre ela, exatamente como se ela jamais houvesse existido. "Suprimir" é a tradução que Lacan fornece em 1956, elevando o termo a designador de uma operação metapsicologicamente específica, tal como o recalque.

O Homem dos Lobos, quanto ao processo envolvido na formação da alucinação de seu dedo cortado, nada quer saber da ameaça de castração. Não no sentido de tê-la, de alguma forma, percebido, para em seguida repudiá-la - como ocorre na combinação recalcado/retorno do recalcado, necessariamente prévia ao uso intelectual da negação - , mas em sentido mais radical de barrar qualquer forma de captação da castração, ou seja, qualquer forma de inscrição simbólica. Torna-se, então necessário, estipular para o caso a atuação de uma operação específica: “[...] no sentido do recalque, sabe-se ainda algo daquilo de que não se quer mesmo, de certa forma, nada saber [...]. Se há coisas de que o paciente não quer nada saber, mesmo no sentido do recalque, isso supõe um outro mecanismo" (LACAN, 1955-1956, p.170). 
Enquanto a negação envolvida na Verneinung exclui algo que se inscrevera previamente, isto é, que fora de algum modo admitido, a negação executada pela Verwerfung nega algo que permanece sem qualquer relação com a qualidade da existência. Ela exige que se estipule uma forma de negação difícil de abordar por se tratar de uma negação que não é simbólica. O que está sendo negado aí é a própria ingerência do simbólico como um todo. A dificuldade de articulála reside justamente em dizer como algo pode ser negado sem que tenha sido antes reconhecido. Mas, por outro lado, se nos ativermos a essa dificuldade, perceberemos o motivo exato por que não se trata aí de uma negação simbólica. Esta sim, exigiria o reconhecimento prévio de algo a ser anulado, ao passo que a Verwerfung é não haver o reconhecimento. A presença da castração surge como fato de estrutura, sem um representante pontual que a designe enquanto estrutura, e é recusada antes que venha, ela mesma, prover as condições que abririam um campo em que questões de reconhecimento tornar-se-iam possíveis.

Por isso a escolha de forclusion para traduzir Verwerfung. Termos como rejeição, supressão, repúdio — de início utilizados — não deixam de possuir uma aproximação semântica forte com a negação nesse sentido que se quer evitar. Já forclusion, termo do léxico jurídico, significando "perda da faculdade de fazer valer um direito pela expiração de um prazo” (MERLET, 2006, p.476), apresenta a vantagem de indicar uma negação que não parte de uma iniciativa subjetiva, mas de um processo, maior do que o sujeito, embora o implique, que lhe retira determinados direitos os quais chegara a possuir quanto à execução de uma ação qualquer. O uso que Lacan faz desse termo, apesar de ter sido originalmente inspirado na tipologia da negação levada a cabo pela gramática de Jacques Damourette e Édouard Pichon - tendo sido especialmente por este já relacionada à teoria psicanalítica — e de ter seguido as pistas de René Lafforgue quanto à aproximação entre psicose e, nesse caso, o procedimento chamado por ele de "escotomização"2 ultrapassa ambas as contribuições sob cruciais aspectos. Quanto à gramática dos franceses, Lacan promove um uso da forclusão que sai do campo da negação intelectual; quanto a Lafforgue, toda a teoria que estamos expondo aqui mostra que a operação em questão sofreu, em suas mãos, uma total ressignificação com ampla modificação de seu solo epistemológico. No caso, a Verwerfung funciona como se retirasse do sujeito o direito de reconhecer sua castração e a presença do Outro. Essa escolha parece conter também a intenção

\footnotetext{
2 Ver Macey, 1988, p.32-41. Lacan faz, ao longo de sua obra, diversas referências a essa gramática, sobressaindo-se a reflexão sobre o trato que ela disponibiliza para a negação expletiva em francês como índice do sujeito da enunciação. Quanto ao fato de ela estar ligada às fontes da teoria da forclusão através da distinção entre "negação forclusiva" e "negação discordancial", ver as sessões 5 e 6 do Seminário 6. Já a "escotomização" encontra-se mencionada nas sessões 4 e 12 do Seminário 3.
} 
de demarcar a ambigüidade do lugar da lei na operação. A forclusion é um processo legal, uma ação que tem origem na lei. Mas para recusar o acesso a um direito que antes fora legitimamente garantido. Ou seja, ela decorre da forma pela qual a lei já existe circulando na configuração edípica encontrada pelo sujeito ao nascer. Representa, então, de algum modo, o fato de que é da própria lei que nasce o obstáculo a lhe impedir o acesso.

A hipótese de Lacan é de que o significante cuja inscrição é recusada retorna na dimensão inapreensível própria ao real, como alucinação e proliferação imaginária: “[...] tudo o que é recusado na ordem simbólica, no sentido da Verwerfung, reaparece no real” (LACAN, 1955-1956/1981, p.21). Retorna de fora, pelo automatismo de repetição característico do significante, mas de um fora que é um dentro recusado como corpo de significante (idem, p.171). O primeiro corpo de significante do psicótico, a primeira concretização da linguagem em seu ser, reverbera do núcleo das cadeias significantes que o atravessam sem jamais chegar a fazer parte delas.

Dos motivos de tal destino, só podemos conhecer a parte que diz respeito ao arranjo concreto do drama edípico. Se ocorre ao sujeito convocar o Nome-do-Pai a partir de um lugar inicial de relação fechada com a mãe, é porque esta executou a função de indicá-lo, apontando para o lugar da lei, anterior ao seu próprio desejo. Lacan destaca, quanto a isso, a importância do pai real. O lugar que ele ocupa frente à relação mãe-criança pode funcionar como obstáculo, conduzindo a primeira a simbolizar a lei. Cabe à mãe, como único Outro a que a criança tem acesso nesse momento, apontar a saída da relação simbiótica pela introdução do complexo de castração. Se esta é entendida como corte da linguagem sobre o ser, separando o acesso ao real sob o modo da perda, sabemos que sua recusa é o esforço para evitar essa perda, um apego ao que Lacan chamará mais tarde de gozo, uma resistência a separar-se do jogo da demanda com a mãe. Nesse lugar, a criança permanece no nível imaginário da identificação fálica; na ausência do Nome-do-Pai, não há como ser gerada a metáfora paterna que conduziria o falo imaginário para o campo do recalcado, elevando-o a falo simbólico, condição para o surgimento da significação fálica, reguladora do deslizamento dos significantes na neurose.

Revela-se, nesse raciocínio, uma sobreposição entre articulação simbólica e Édipo, na qual "Nome-do-Pai sobre Desejo da mãe” é a substituição de relações imaginárias diretas pela intermediação irreversível do simbólico. Aceitar a existência da castração é aceitar, de alguma forma, a inexistência de um mundo de coisas disponíveis a uma experiência imanente. Mas, para o ser humano, não há tal possibilidade, e o que o psicótico ganha com a recusa não é um acesso direto às coisas, mas um tipo diferenciado de remissão à totalidade da linguagem como destino da fala. A relação com o Outro é da ordem de uma violência 
imaginária que assalta o corpo pelo deslizamento de significações desvinculadas do significante que representa a possibilidade da significação. Na ausência de uma mediação simbólica, produz-se uma mediação pela produção de imagens a partir de um significante que, excluído, reaparece no real. Tudo se passa como se o sujeito se dirigisse a um Outro sem significância, por faltar a metáfora que o representaria e garantiria a conexão de cada significante com os demais, resultando no fato de que a pulsão, impedida de circular no simbólico, se projetasse na multiplicação de imagens.

O Outro não se encontra excluído de forma absoluta, mas sob um modo. O que falta é uma representação de seu lugar ou de sua função na medida que poderia instaurar a anterioridade do simbólico em relação à produção de realidade e um descolamento entre o sujeito e o gozo. Mas a ausência de inscrição do simbólico enquanto estrutura não equivale a uma ausência absoluta do simbólico no universo psicótico. São provas disso sua produção discursiva e sua produção de delírio. O que acontece é que o significante aparece como que precipitado, hipostasiado, caído do lugar do Outro, descosturado de uma convergência fálica e tendo que ser submetido a uma lógica imaginária (LACAN, 1959b/1966, p.584).

O símbolo suprimido da Bejahung não passa à existência, uma vez que não entra no jogo de reconhecimento proporcionado pela fala. Ele ex-siste, o que significa que se torna efetivo a partir de um real puro, insistindo do lado de fora da estrutura e excluído das operações de substituição que esta poderia prover. Trata-se, no psicótico, de uma falha na função de nomeação, inexistindo algo que separe o mundo para o sujeito, separação que lhe forneceria a possibilidade de que, para si mesmo, ele também pudesse ser nomeado.

Isso significa que, para costurar a linha da cadeia significante, falta-lhe a linha do discurso racional que já abriga certo número de referências compartilhadas e definidas pelo uso que delas é feito: é “[...] o nível em que se produz o mínimo de criações de sentido, uma vez que, nele, o sentido já está dado de alguma forma. Na maior parte do tempo, esse discurso consiste apenas numa mistura dos ideais recebidos" (LACAN, 1957-1958/1998, p.16). Aqui, caímos na discussão sobre a existência de certo elemento pragmático no raciocínio lacaniano. Mas ele surge com o nível do determinado e não da determinação, no qual se situam agora os critérios sociais. No trecho citado, ele é indicado diretamente e vemos que está relacionado à criação da realidade e não da verdade, a qual não pertence ao discurso racional, mas à cadeia significante.

Esse discernimento é o que permite entender como pode ser atribuído um valor axial à racionalidade estruturalista para uma teoria da psicose: tudo se passa como se o Lacan da tese de doutorado tivesse permanecido restrito ao nível do discurso racional, socialmente distribuído, tendo que localizar no mesmo ponto - a resposta subjetiva ao contexto - a explicação tanto da psicose quanto da 
personalidade em geral. Agora, ele encontra algo que pode agir como fator de esclarecimento desse plano sociológico, revelando ser-lhe anterior. A determinação simbólica, pela contingência da inscrição de um significante, responde por ambas as causalidades, descrevendo um mecanismo para cada uma das afecções. A admissão do registro simbólico mostra que é preciso ir além do campo da realidade comungada para que se torne possível aquilatar a diferença entre neurótico e psicótico. Dessa forma, encontrando a razão inaparente, ele pode abster-se de pensar a constituição do mundo como fenômeno paranóico.

Por aí, tornou-se possível criticar a abordagem da escola kleiniana da questão, crítica na qual parece reconhecer o paradoxo presente em sua própria teoria de 1932:

“Aí está o que podemos realmente chamar de uma construção psicótica do sujeito. Um sujeito normal é, em suma, dentro dessa perspectiva, uma psicose que deu certo, uma psicose afortunadamente harmonizada com a experiência. [...] o sr. Winnicott, exprime-o exatamente assim [...] a homogeneidade fundamental da psicose com a relação normal com o mundo é absolutamente afirmada como tal." (LACAN, 1957-1958/1998, p.216)

A saída do impasse é apontada, em seguida, na necessidade de reconhecer aquilo que representa a estrutura simbólica:

"Para completar a dialética kleiniana, é preciso introduzir essa noção de que o exterior, para o sujeito, é inicialmente dado não como algo que se projeta a partir do interior do sujeito, de suas pulsões, mas como o espaço, o lugar onde se situa o desejo do Outro e onde o sujeito tem que ir encontrá-lo." (LACAN, 1957-1958/1998, p.272)

A constituição "normal" do sujeito mantém a ilusão imaginária, mas esse processo encontra ao mesmo tempo seu limite e sua anterioridade numa intersubjetividade peculiar: a relação do sujeito com o Outro de uma forma específica que falta ao sujeito psicótico.

Tendo em vista todos esses aspectos da teoria, podemos tentar entender agora por que Lacan busca apoio na Verwerfung e não na Verleugnung, direcionando-se no sentido contrário de diversas pistas deixadas por Freud quando trabalhava esse segundo termo, sobretudo a propósito do fetichismo. Lacan, evidentemente, não desconhecia essa alternativa, comentando-a na sessão XI do Seminário 3. Mas, de fato, se considerarmos que a Verleugnung é, para Freud, indissociável da delimitação de um registro mnêmico da castração e que se busca aqui, ao contrário, isolar um mecanismo em que tal registro estaria ausente, torna-se compreensível que 
ele seja procurado noutro lugar. Como explica Simanke, sintetizando esse ponto descritivo da Verleugnung:

“[...] não se trata de uma anulação completa da percepção [...]. Ao contrário, tanto é verdade que a percepção permanece, que um esforço enérgico é feito para renegá-la. Aqui tem-se uma situação algo análoga à descrita no texto sobre a Verneinung. Alguma forma de afirmação é suposta e surge como lógica e geneticamente anterior à ação, essencialmente negativa, dos mecanismos de defesa." (1994, p.206-7)

Enquanto o recalque e a Verneinung rejeitariam um representante de pulsão, a Verleugnung (recusa) teria por alvo um dado perceptivo, mas somente na medida que dele se apresentasse algum registro, não podendo aparecer como “[...] uma cegueira psíquica absoluta frente ao dado perceptivo" (SIMANKE, 1994, p.207).

Ora, o que está em pauta aqui não é nada mais do que o fato de serem tomadas, no raciocínio lacaniano, premissas diversas das freudianas e a motivação de fundo para o deslocamento dos termos implicados é exatamente a camada de sentido sobreposta pelas exigências da estrutura. Trata-se de questionar o modo de submissão ao simbólico, de investigar que tipos de conseqüências podem ser atribuídos a acidentes nesse processo, de especular as interseções que pode haver entre patologias e a relação do homem à existência dos significantes. Pois, se Lacan partiu do pequeno texto sobre a negação, foi para tentar descrever um mecanismo de defesa que, de tão arcaico, antecedesse o requisito que é nele apresentado, procurando pensar uma operação que, anterior a qualquer forma de afirmação, explicasse algo das condições da própria afirmação. Se é possível entrever, no comentário que Freud faz do Homem dos Lobos, um acontecimento psíquico que, diante da castração, se comporta com a total carência de registro, então ele de fato tem maiores chances de chegar a exprimir de maneira apropriada a relação entre simbólico e real, tornando-se capaz de armazenar um questionamento da ausência de inscrição da castração como fator discriminante da psicose. Dito de outro modo, se a Verwerfung isenta o aparelho da necessidade de qualquer traço da castração, ela é mais adequada para denominar a não-Bejahung do que a Verleugnung, transformando a questão patológica em questão estrutural. Portanto, o que interessa averiguar não é se a leitura de Freud realizada por Lacan foi "bem feita” — se procurou compreender o que o fundador da psicanálise "realmente quis dizer" — mas o valor da teoria que ele próprio passa a disponibilizar.

E por fim podemos retornar à questão da tendência a conjugar a psicose com algo arcaico da subjetividade de forma geral. O percurso torna a questão sur- 
preendente: como podemos voltar a levantar essa possibilidade se acabamos de dizer que o estruturalismo traz à psicanálise lacaniana a ocasião de finalmente pensar a psicose exatamente em sua diferença? Ocorre que é justamente por ser uma diferença que ela revela uma condição geral, uma vez que se trata de uma diferença que manifesta um momento primitivo. De todo modo, ela mostra que, antes de qualquer estrutura de sujeito, há cumplicidade entre real e simbólico, que primeiramente existe o mundo da linguagem, que este deve ser admitido pelo sujeito, que esta admissão é um fato contingente e não necessário. Dito de outro modo, a psicose explica um aspecto da neurose (ter havido a Bejahung) na medida que ela é a não-Bejahung e traz à escuta psicanalítica o eco desse tempo anterior. O seguinte comentário é bem elucidativo nesse sentido:

\footnotetext{
“Previamente a toda simbolização — essa anterioridade não é cronológica, mas lógica - há uma etapa, as psicoses o demonstram, em que é possível que uma parte da simbolização não se faça. Essa etapa primeira precede toda a dialética neurótica [...]. Pode, assim ocorrer que alguma coisa de primordial quanto ao ser do sujeito não entre na simbolização, e seja, não recalcado, mas rejeitado." (LACAN, 1955-1956/1981, p.94)
}

Além de resguardar uma negação mais arcaica, livrando a Verleugnung para o mecanismo de defesa implicado na perversão, a Verwerfung se aproxima dos comentários de Freud sobre a projeção, sendo capaz de substituí-la. Às vezes envolvida com a defesa primária que produz a psicose, às vezes apenas com o nível de formação do sintoma psicótico, a projeção apareceu, no caso Schreber, com uma estrutura muito parecida com aquela que Lacan quer destacar. No contexto, Freud está se referindo a laços libidinais afetuosos abandonados que retornam, do exterior, como hostis: "Não era correto dizer que a sensação interiormente sufocada é projetada para fora; mas bem percebemos que o que fora cancelado dentro retorna desde fora" (FREUD, 1911/1989, p.66). Traduzir essa expressão para “o que é abolido no simbólico retorna no real” não revela apenas uma preferência por determinado vocabulário, mas dispensa, no limite, a oposição dentro/fora quando o ponto de referência é o sujeito, reservando-a como questão exclusivamente de ordem imaginária. O fato de entender esse processo a partir da Verwerfung em vez da projeção dá continuidade à necessidade epistemológica de suprimir resquícios de psicologismo, possibilitando a coerência com o viés externalista na leitura da psicose.

Dessa forma, podemos sustentar que o estruturalismo, além de promover, pelo efeito deletério da não-inscrição do Nome-do-Pai, a via da construção de uma teoria da determinação específica da psicose, não a retira de seu lugar de privilégio no raciocínio lacaniano, estabelecendo, pela distinção simbólico/real, 
as conexões que fazem dessa patologia um fenômeno revelador das relações primeiras do ser humano com a linguagem.

Assim, afastada das intenções de compreensão e fundamentada na articulação significante, essa teoria estruturalista não precisa ser tomada como fenômeno de conhecimento no sentido que vinha sendo discutido. Ou seja, a inserção do simbólico, pela dissociação entre conhecimento e verdade, apresenta uma teoria da paranóia que, nos moldes descritos pelo trato do caso Aimée, não precisa ser considerada, ela também, um fenômeno paranóico.

Recebido em 30/10/2006. Aprovado em 29/1/2007.

\section{REFERÊNCIAS}

BALMÈS, F. (1999) Ce que Lacan dit de l'être. Paris: PUF.

FREUD, S. (1989) Obras completas de Sigmund Freud. Buenos Aires: Amorrortu.

(1911) "Puntualizaciones psicoanaliticas sobre un caso de paranoia (Dementia paranoides)", v.12, p.1-76.

(1918) “De la historia de una neurosis infantil”, v.17, p.1-112.

(1925) “La negación”, v.19, p.250-257.

KOJÈVE, A. (1947) Introduction à la lecture de Hegel. Paris: Gallimard.

LACAN, J. (1932/1987) Da psicose paranóica em suas relações com a personalidade. Rio de Janeiro: Forense. (1938) "La familla”, in Encyclopédie Française, v.VIII, La vie mentale. Paris: Larousse.

. (1953-1954/1975) Le Séminaire livre I, Les éscrits techniques de Freud. Paris: Seuil.

. (1955-1956/1981) Le Séminaire livre III, Les psychoses. Paris: Seuil. (1956/1966) "Réponse au commentaire de Jean Hyppolite sur la “Verneinung” de Freud”, in Écrits. Paris: Seuil.

. (1957-1958/1998) Le Séminaire, livre V, Les formations de l'inconscient. Paris: Seuil.

(1958-1959) Le désir et son interprétation — Seminaire 1958-1959. Inédito. Consultado na versão da AFI.

(1959a/1966) “A la mémoire d’Ernest Jones: Sur sa théorie du symbolisme”, in Écrits. Paris: Seuil.

(1959b/1966) "D’une question préliminaire à tout traitement possible de la psychose”, in Écrits. Paris: Seuil.

(1961-1962) L’identification — Séminaire 1961-1962. Inédito.

Consultado na versão da AFI. 
MACEY, D. (1988) Lacan in contexts. Londres/Nova York: Verso.

MERLET, P. (2006) (dir.) Le pétit Larousse illustré. Paris: Larousse.

RICOEUR, P. (1970) “Estrutura e hermenêutica”, in LIMA, L. C. (org.). O estruturalismo de Lévi-Strauss. Petrópolis: Vozes.

SIMANKE, R. T. (1994) A formação da teoria freudiana das psicoses. Rio de Janeiro: 34 .

Léa Silveira Sales

lea_silveira@uol.com.br 